\title{
THE PEAT AND WOOD GASIFICATION AT DIFFERENT CONDITIONS OF THE PYROLYSIS PROCESS
}

\author{
Dmitriy Portnov ${ }^{1 \mathrm{a}}$, Dmitriy Subbotin ${ }^{1}$, Alexander Kazakov $^{1}$, Alexander Zavorin ${ }^{1}$ \\ ${ }^{1}$ National Research Tomsk Polytechnic University, 634050 Tomsk, Russia
}

\begin{abstract}
In this article are described the prospects of peat and wood using as a raw material for gasification with producing of high potential synthesis gas. It is shown that the low-grade fuel recycling, in particular wood and peat makes a use of this energy sources a possible alternative to the using a more traditional coal and natural gas. The features of low-temperature pyrolysis are analyzed and computer modeling of this process at different conditions is conducted. The temperature influence of recycling to main parameters (calorific value, elementary composition of gaseous components) of produced gas is established.
\end{abstract}

\section{Introduction}

The industrial peat and wood gasification is a complex chemical process, which includes the different reactions and transformations. It is usually performed in a limited presence of oxygen. The universal description of the processes, which occurred during the pyrolysis, does not exist, because these processes are multicomponent and multifactor [1].

A thermal decomposition of complex biological compounds starts at a temperature about $100{ }^{\circ} \mathrm{C}$. A decomposition of basic substances during the pyrolysis begins to occur at temperature about $200{ }^{\circ} \mathrm{C}$, but the main processes occur at temperatures above $400{ }^{\circ} \mathrm{C}$ [2].

A pyrolysis is one of the most important chemical processes, which used in power engineering and different industrial manufactures: metallurgy, petrochemistry, etc. For example, by dint of pyrolysis are produced economically and technically important substances such as charcoal, coke, synthesis gas, divinyl, ethylene, propylene, benzene [3-5].

The generator gas as a fuel has doubtless advantages over direct combustion of peat and other biomass. The generator gas, such a natural gas, may be passed to large distances through pipelines and in balloons; it is convenient to use in the home for cooking, for warming and water heating, as well as in industrial and power plants [6-9].

\section{The initial data}

The process of researched low-temperature pyrolysis is considered by three main reactions [10-12]:

1) $\mathrm{C}+\mathrm{O}_{2}=\mathrm{CO}_{2}$; 2) $\left.\mathrm{C}+2 \mathrm{H}_{2}=\mathrm{CH}_{4} ; 3\right) \mathrm{C}+\mathrm{H}_{2} \mathrm{O}=\mathrm{CO}+\mathrm{H}_{2}$. The reactions 1 and 2 are standard with known equilibrium constants. The reaction 3, taking into account the presence of a catalyst and high-temperature steam, is not standard. For this reaction, is experimentally determined the equilibrium constant, which depends on the process temperature and the type of fuel. The program for calculation of the thermal decomposition process of solid fuels at low temperatures in high temperature steam conditions and catalyst presence is developed [13-16]. The calculation algorithm based on the following dependences:

$$
\begin{gathered}
\left\lfloor\mathrm{CO}_{2}\right\rfloor=K \cdot w \cdot \mathrm{O}_{2} ; \\
{\left[\mathrm{CH}_{4}\right]=K \cdot \frac{\left(w \cdot \mathrm{H}_{2}\right)^{2}}{\left[\mathrm{H}_{2}\right]} ;} \\
{[\mathrm{CO}]=\frac{w\left[\mathrm{H}_{2} \mathrm{O}\right] \cdot c \cdot K}{\left[\mathrm{H}_{2}\right]} ;}
\end{gathered}
$$

$\left[\mathrm{H}_{2}\right]=4 \cdot 10^{-7} \cdot \mathrm{T}^{3}-0,0009 \cdot \mathrm{T}^{2}+0.5189 \cdot \mathrm{T}-41,667-$ for peat;

$\left[\mathrm{H}_{2}\right]=-3 \cdot 10^{-6} \cdot \mathrm{T}^{3}+0,0029 \cdot \mathrm{T}^{2}-0.3305 \cdot \mathrm{T}+39-$ for wood;

$\left[\mathrm{H}_{2}\right]=0,0008 \cdot \mathrm{T}^{2}-0.0036 \cdot \mathrm{T}-10-$ for brown coal,

where: $\left[\mathrm{CO}_{2}\right],\left[\mathrm{CH}_{4}\right],\left[\mathrm{H}_{2}\right]$ - the amount of generated gas components;

$K$ - the reaction equilibrium constants;

\footnotetext{
${ }^{a}$ Corresponding author: portnov_1992@mail.ru
} 
$w$ - the amount of elements, passed from a fuel in a gas;

$T$ - the process temperature;

$c$ - the degree of steam decomposition;

$\mathrm{O}_{2}, \mathrm{H}_{2}, \mathrm{H}_{2} \mathrm{O}$ - the initial content of components in a fuel.

The program allows carrying out a various calculations of the final gas composition, specifying the initial fuel composition and process temperature.

One of important solid fuel characteristics is working moisture. Therefore, is important to determine influence of this characteristic on the pyrolysis. For this, the elementary composition of researched fuel has been recalculated for various values of moisture, in the range from 20 to $50 \%$ (Table 1).

Table 1. The elementary composition of wood and peat with different moisture.

\begin{tabular}{|c|c|c|c|c|c|c|c|c|c|c|c|c|c|}
\hline $\begin{array}{c}\mathrm{C}_{\mathrm{w}}, \\
\%\end{array}$ & $\begin{array}{c}\mathrm{H}_{\mathrm{w}}, \\
\%\end{array}$ & $\begin{array}{c}\mathrm{S}_{\mathrm{w}}, \\
\%\end{array}$ & $\begin{array}{c}\mathrm{N}_{\mathrm{w}}, \\
\%\end{array}$ & $\begin{array}{c}\mathrm{O}_{\mathrm{w}}, \\
\%\end{array}$ & $\begin{array}{c}\mathrm{A}_{\mathrm{w}}, \\
\%\end{array}$ & $\begin{array}{c}\mathrm{W}_{\mathrm{w}}, \\
\%\end{array}$ & $\begin{array}{c}\mathrm{C}_{\mathrm{p}}, \\
\%\end{array}$ & $\begin{array}{c}\mathrm{H}_{\mathrm{p}}, \\
\%\end{array}$ & $\begin{array}{c}\mathrm{S}_{\mathrm{p}}, \\
\%\end{array}$ & $\begin{array}{c}\mathrm{N}_{\mathrm{p}}, \\
\%\end{array}$ & $\begin{array}{c}\mathrm{O}_{\mathrm{p}}, \\
\%\end{array}$ & $\begin{array}{c}\mathrm{A}_{\mathrm{p}}, \\
\%\end{array}$ & $\begin{array}{c}\mathrm{W}_{\mathrm{p}}, \\
\%\end{array}$ \\
\hline 38,75 & 9,45 & 0,05 & 0,55 & 31 & 0,2 & 20 & 33,235 & 10,928 & 0,266 & 1,064 & 22,600 & 11,923 & 20 \\
\hline 36,33 & 8,859 & 0,047 & 0,516 & 29,06 & 0,188 & 25 & 31,034 & 10,204 & 0,248 & 0,993 & 21,103 & 10,357 & 25 \\
\hline 33,91 & 8,268 & 0,044 & 0,482 & 27,12 & 0,176 & 30 & 28,834 & 9,480 & 0,231 & 0,923 & 19,607 & 10,204 & 30 \\
\hline 31,49 & 7,677 & 0,041 & 0,448 & 25,18 & 0,164 & 35 & 26,633 & 8,757 & 0,213 & 0,852 & 18,110 & 9,567 & 35 \\
\hline 29,07 & 7,086 & 0,038 & 0,414 & 23,24 & 0,152 & 40 & 24,432 & 8,033 & 0,195 & 0,782 & 16,614 & 8,776 & 40 \\
\hline 26,65 & 6,495 & 0,035 & 0,38 & 21,3 & 0,14 & 45 & 22,232 & 7,310 & 0,178 & 0,711 & 15,117 & 7,986 & 45 \\
\hline 24,23 & 5,904 & 0,032 & 0,346 & 19,36 & 0,128 & 50 & 20,031 & 6,586 & 0,160 & 0,641 & 13,621 & 4,195 & 50 \\
\hline
\end{tabular}

$\mathrm{i}_{\mathrm{w}}$ - values for wood; $\mathrm{i}_{\mathrm{p}}$ - values for peat; $\mathrm{C}$ - carbon content; $\mathrm{H}$ - hydrogen content; $\mathrm{S}$ - sulfur content; $\mathrm{N}$ - nitrogen content; $\mathrm{O}$ - oxygen content; A - fuel ash content; $\mathrm{W}$ - fuel moisture.

\section{The research of gas composition and calorific value in depending of different parameters}

The gas, which produced during gasification, contains a certain amount of components; it is shown in Fig. 1, 3.

The calorific value of produced gas depends on the type of used raw materials and gasification conditions; it is shown in Fig. 2 , 4.

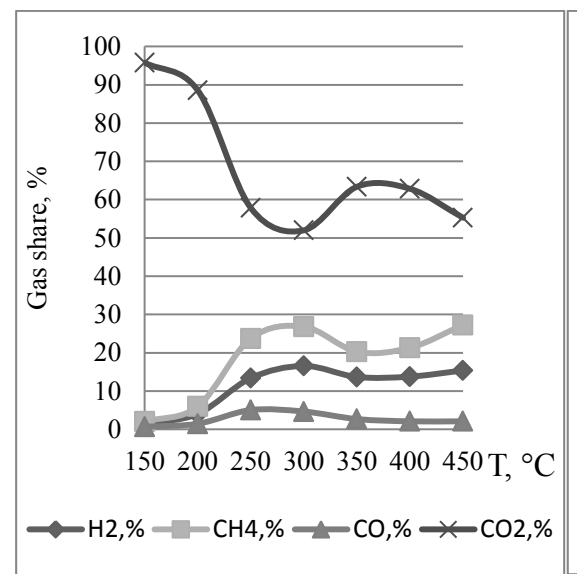

Figure 1. The dependence of gas composition from recycling temperature $(\mathrm{T})$ of peat

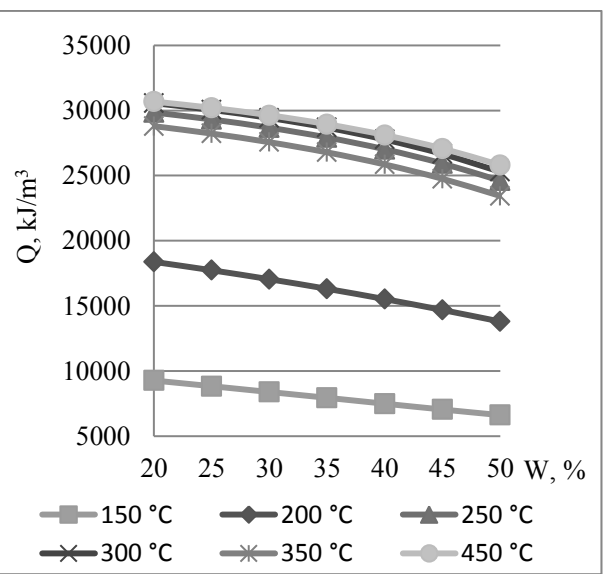

Figure 2. The dependence of gas calorific value (Q) from moisture (W) of peat 


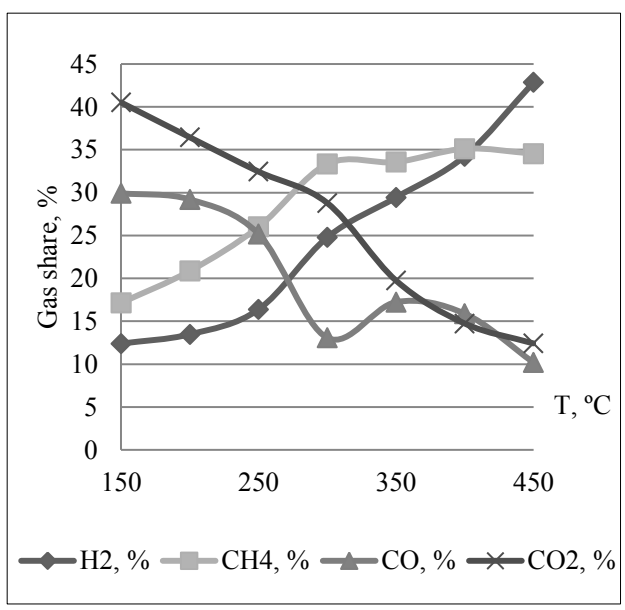

Figure 3. The dependence of gas composition from recycling temperature $(T)$ of wood

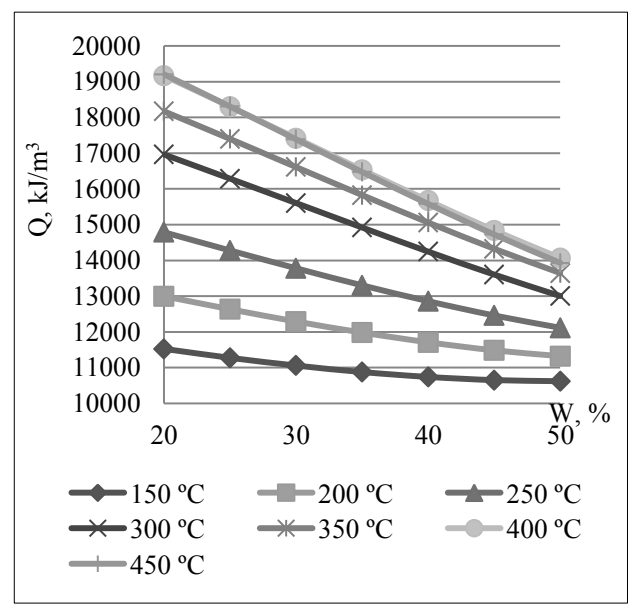

Figure 4. The dependence of gas calorific value (Q) from moisture $(\mathrm{W})$ of wood

The gasification of a more moist peat and wood is reduced the gas yield, what is seen from obtained dependences (Fig. 2, 4). This occurs because a significant part of energy is expended to the evaporation of water, which contains in a fuel.

With increase of the hydrogen content in a peat $(\mathrm{H})$, is an increase of combustible component methane $\left(\mathrm{CH}_{4}\right)$, it is shown in obtained dependence (Fig. 6).

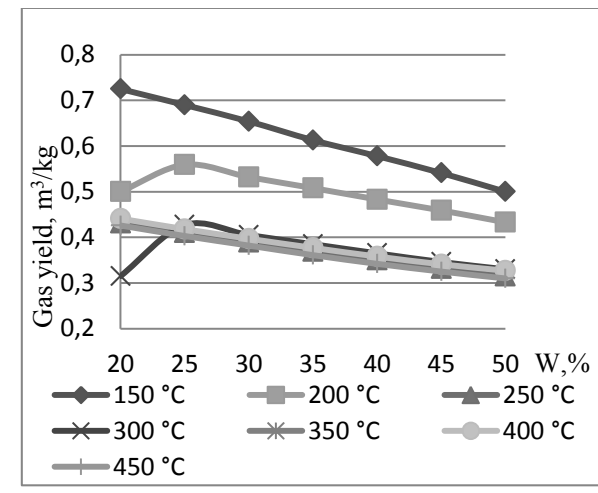

Figure 5. The dependence of gas yield from moisture (W) of peat

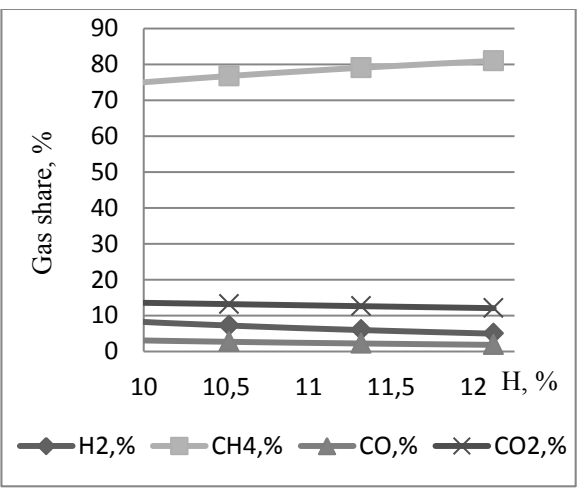

Figure 6. The dependence of gas yield from hydrogen content $(\mathrm{H})$ in peat

From dependence (Fig. 7) is seen that increase of carbon monoxide $(\mathrm{CO})$ content and reduction of methane $\left(\mathrm{CH}_{4}\right)$ is a result of an increasing of oxygen $\left(\mathrm{O}_{2}\right)$ in peat. That negatively effects on the gas calorific value.

From dependence (Fig. 8) is seen that increase of methane $\left(\mathrm{CH}_{4}\right)$ content is a result of an increasing of carbon $(\mathrm{C})$ in peat. That positively effects on the gas calorific value. 


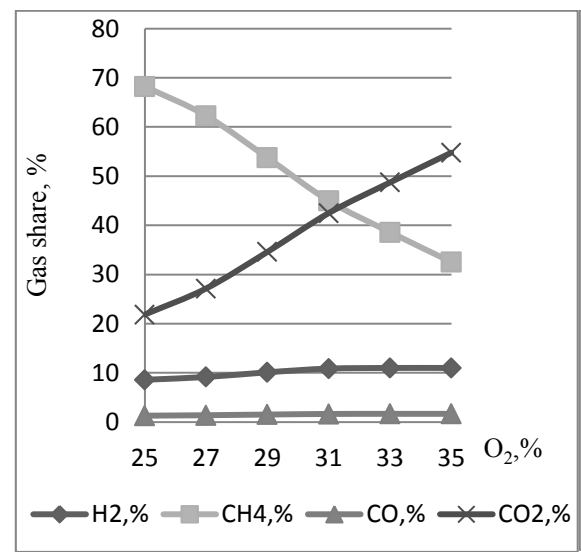

Figure 7. The dependence of gas yield from oxygen $\left(\mathrm{O}_{2}\right)$ content in peat

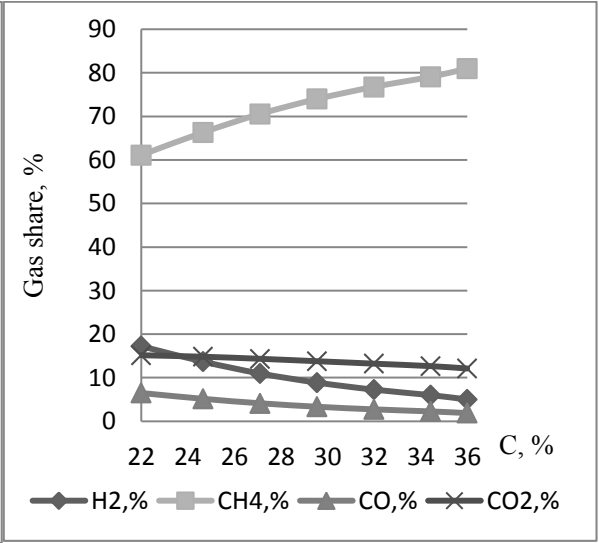

Figure. 8. The dependence of gas yield from carbon (C) content in peat

\section{The analysis of results and conclusions}

At carrying out of this research with using of computer modeling techniques were established visual dependences between fuel properties, recycling parameters and quality of produced gas.

The importance of temperature influence at gasification process on its results, particularly on the gas yield and his calorific value, was determined. Also, the temperature $\left(300\right.$ and $\left.450^{\circ} \mathrm{C}\right)$, at which increases a methane yield from peat, was established, as consequence, increases amount of produced gas and his calorific value. In general, as the temperature increases, there is improvement of main parameters of the produced gas. At that, by comparing of the results of wood gasification at different moisture was established optimum value $25-30 \%$, at which a temperature influence of process does not much affects by result. This allows to use a low-temperature pyrolysis for producing gas with acceptable parameters. However, a considerable reduction of final product properties is observed at the increasing of fuel moisture.

Besides of moisture and recycling temperature, a great impact to pyrolysis process renders the elementary composition of peat and wood. Firstly, this applies of oxygen, hydrogen and carbon.

The increased of hydrogen share in a recycling feedstock, conversely, renders a positive effect to gas quality. The gas calorific content increases due to the greater amount of methane and hydrogen. Due to the hydrogen excess, it begins more intensively react with carbon, as a consequence, methane yield increases and amount of carbon oxides reduces.

The increase of oxygen content in initial fuel leads to increase $\mathrm{CO}_{2}$ share in the generator gas, thereby reducing the combustible components formation, as methane, as a result the gas calorific value reduces.

With increase of carbon content, specific gas calorific value reduces because of increasing $\mathrm{CO}$ and $\mathrm{CO}_{2}$ share.

Summarizing, we can say that this researching is confirmed the high potential of peat and wood using for synthesis gas production by catalytic pyrolysis.

The reported study was partially supported by the Ministry of education and science of The Russian Federation (Government Order No. 13.948.2014/K and Government Order No. 2069).

\section{References}

1. P. Jame, E. Bonjour, M. Batteau, C. Jose, P. Paul, J. Ponthus, A. Quignard, N. Charon, Energy and Fuels, 29, 3176 (2015).

2. B. Zhang, Y. Wang, Biomass processing, conversion and biorefinery (New York, Nova Science Publishers, 2013).

3. K. Promdee, T. Vitidsant, Coke and chemistry, 56, 466 (2013).

4. T. Aysu, Bioresource Technology, 191, 253 (2015).

5. I. Sircar, A. Sane, W. Wang, J.P. Gore, Fuel, 119, 38 (2014).

6. A.S. Zavorin, A.V. Kazakov, A.A. Makeev, S.V. Podorov, Thermal Engineering, 57, 77 (2010).

7. A.V. Kazakov, R.B. Tabakaev, P.Y. Novoseltsev, A.V. Astafev, MATEC Web of Conferences, 19, 01014 (2014).

8. A.S. Zavorin, R.B. Tabakaev, P.Y. Novoseltsev, A.V. Astafev, MATEC Web of Conferences, 19, 01015 (2014).

9. S.A. Khaustov, A.S. Zavorin, K.V. Buvakov, V.A. Sheikin, EPJ Web of Conferences, 82, 01039 (2015)

10. R.B. Tabakaev, A.V. Astafev, A.V. Kazakov, A.S. Zavorin, MATEC Web of Conferences, 23, 01039 (2015).

11. N.V. Suglobova, T.M. Plakhova, A.V. Kazakov, A.S. Zavorin, 9th International Forum on Strategic Technology, 2014, p. 386.

12. P.S. Gergelizhiu, S.A. Khaustov, R.B. Tabakaev, P.U. Novoseltsev, A.V. Kazakov, A.S. Zavorin, Proc. of 2014 International Conference on Mechanical Engineering, Automation and Control Systems, 2014, 6986901.

13. R.B. Tabakaev, P.S. Gergelizhiu, A.V. Kazakov, A.S. Zavorin, IOP Conference Series: Materials Science and Engineering, 66, 012052 (2014). 


\section{Smart Grids 2015}

14. R.B. Tabakaev, A.V. Kazakov, A.S. Zavorin, Solid Fuel Chemistry, 49, 267 (2015).

15. A.V. Kazakov, T.M. Plakhova, R.I. Popov, MATEC Web of Conferences, 19, 01019 (2014).

16. R.B. Tabakaev, A.V. Astafev, A.V. Kazakov, A.S. Zavorin, MATEC Web of Conferences, 23, 01040 (2015). 